\title{
Strategi Manajemen Mengoptimalkan Kinerja Dengan Konsep Beyond Budgeting
}

\author{
Badar Murifal \\ Program Studi Sistem Informasi Akuntansi. Fakultas Teknik dan Informatika \\ Universitas Bina Sarana Informatika \\ Correspondence email: badar.bml@bsi.ac.id
}

\begin{abstract}
There are two important elements that create an environment of high freedom for managers and employees, namely the company management culture and the availability of a clear information system as the basis for the management process. The new model of leadership is based on the principle of empowering managers and employees, as well as an adaptable management process. This new leadership principle must be able to unlock all potential managers and employees in running the organization so that they can react appropriately and quickly when facing new opportunities and market risks. To be successful, members of the beyond budgeting project must include control specialists, human resource management, change management, and computer experts. Not all companies are able to provide all the required resources. In traditional budgeting systems, targets are set based on financial figures and are negotiated centrally. In beyond budgeting, targets are based on high key performance indicators, such as the ratio of return on capital, free cash flows or cost to income. Performance appraisals are no longer carried out for the long term (annually), but are carried out in a shorter period of time on a regular basis and are rolling and decentralized. Beyond Budgeting is the idea of abolishing traditional budgeting processes to eventually improve management control over an organization. By abandoning traditional budgeting processes, a company aims to establish a highly decentralized organizational system and adaptive set of management processes.
\end{abstract}

Keywords: Management Process; Beyond Budgeting; Performance

\section{PENDAHULUAN}

Dalam mencapai tujuannya sebuah perusahaan membutuhkan anggaran untuk menerjemahkan strategi ke dalam rencana dan tujuan jangka pendek dan jangka panjang. Anggaran merupakan rencana keuangan untuk masa depan, dimana rencana tersebut mengidentifikasi tujuan dan tindakan yang diperlukan untuk mencapainya. Dewasa ini, anggaran dikatakan terlalu kompleks dan tidak fleksibel. Anggaran yang dibuat dengan mengorbankan sumber daya yang besar ternyata tidak mampu beradaptasi cukup cepat dengan perubahan pasar yang dinamis karena sifatnya yang tidak responsif dan fleksibel. Sistem penganggaran juga terlalu berfokus pada pengurangan biaya, bukan pada pembentukan nilai (value).Selain itu, anggaran juga dikatakan memberi batasan bagi para manajer, sehingga tidak memotivasi manajer untuk mencapai target yang lebih tinggi. Anggaran juga dikatakan bertindak sebagai penghalang perubahan fundamental. Anggaran tradisional menahan perusahaan untuk bergerak maju, membatasi kreativitas karyawan dan mencegah mereka untuk menanggapi kebutuhan pelanggan. Banyaknya komentar negatif terhadap sistem penganggaran tradisional, sehingga memunculkan pemikiran mengenai penganggaran yang lebih baik. Sumber inspirasi untuk beyond budgeting adalah filosofi dari Jan Wallander dari Svenska Handelsbanken, sebuah Bank Swedia yang tidak memiliki anggaran sejak tahun 1970. Model manajemen Handelsbanken yang diperkenalkan oleh Wallander merupakan sebuah model yang sederhana dengan hierarki yang mendatar dengan beberapa pengendali, pegawai yang terlatih, dan tanpa anggaran sebagai penghalang, serta beberapa pengukuran kinerja yang mudah dimengerti. Model ini dibentuk dengan kepercayaan bahwa keunggulan kompetitif yang dimiliki perusahaan di dunia yang bergerak dengan sangat cepat ini terletak pada orang orangnya, terutama kreativitas, wawasan, dan penilaian mereka.

Penelitian ini mempunyai tujuan untuk memberikan bukti empiris dan menganalisis bagaimana suatu laporan keuangan perusahaan dapat dianalisa lebih jauh untuk menghasilkan suatu kesimpulan seberapa besar beyond budgeting dapat dihasilkan dengan variable-variabel yang tersedia.

\section{Kajian Pustaka}

Budgeting harus bersifat realistis, Artinya harus sesuai dengan kondisi keuangan perusahaan. Tidak sengaja melebihkan untuk mendapatkan ekspetasi lebih walau secara laporan yang ada hal itu tidak mungkin. Budgeting harus bersifat fleksibel, Dapat menyesuaikan dengan kondisi (Gunawan, Asri, 2003). Beyond budgeting menurut terminologi resmi The Chartered Institute of Management Accountants (CIMA) adalah sebuah ide yang dperlukan perusahaan untuk bergerak melampaui (beyond) anggaran karena adanya kelemahan yang melekat dalam penganggaran terutama bila digunakan untuk mengatur kontrak. Dikatakan bahwa berbagai teknik, seperti peramalan 
bergulir (rolling forecasts ) dan target terkait pasar (market related targets), dapat mengambil posisi penganggaran tradisional. Beyond budgeting merupakan satu set prinsip - prinsip, yang jika diikuti, akan memungkinkan organisasi untuk mengelola kinerja dan desentralisasi proses pengambilan keputusan tanpa memerlukan anggaran tradisional. Tujuannya adalah untuk memungkinkan organisasi untuk memenuhi faktor -faktor keberhasilan dari informasi ekonomi (misalnya untuk bersikap adaptif dalam kondisi tak terduga).

Beyond budgeting berbeda dengan sistem penganggaran tradisional dalam dua hal mendasar.

1. Sistem pengendalian yang bersifat lebih adaptif. Manajer tidak dinilai berdasarkan suatu perencanaan dan anggaran tahunan, melainkan dengan melakukan suatu perbandingan (benchmark) dengan pesaing, rekan kerja, dan periode sebelumnya, serta dilakukan secara teratur. Benchmarking adalah sebuah proses pembelajaran dan perbandingan dengan organisasi lain dalam melakukan proses dan aktivitas yang sama. Perbandingan ini dapat dilakukan dengan pihak internal perusahaan atau pihak eksternal perusahaan, yang memang dikenal memiliki kinerja yang baik.

2. Beyond budgeting menekankan pada sistem yang terdesentralisasi. Pengambilan keputusan dan pertanggungjawaban kinerja diserahkan kepada manajer lini dan menciptakan lingkungan kerja yang mandiri dan budaya tanggung jawab pribadi. Hal ini menyebabkan peningkatan motivasi, produktivitas yang lebih tinggi dan layanan pelanggan yang lebih baik.

Sumber daya manusia merupakan aset terbesar organisasi. Beyond budgeting melepaskan orang-orang yang memiliki kemampuan dari rantai kontrak kinerja yang bersifat top-down dan memungkinkan mereka untuk menggunakan sumber daya pengetahuan organisasi untuk memuaskan pelanggan dan menghadapi persaingan secara konsisten. Dengan beyond budgeting, para manajer tidak lagi menghabiskan waktu mereka untuk menegosiasikan anggaran yang akan dibentuk, yang nantinya akan menjadi standar penilaian kinerja mereka, melainkan menciptakan nilai bagi pelanggan dan pemegang saham. Beyond budgeting tidak bergantung pada perencanaan, tapi pada kesepakatan kelompok atau pasar dan karenanya dapat beradapsi dngan baik pada lingkungan yang bergolak. Namun, koordinasi melalui kesepakatan tidak dapat dilakukan secara efisien dalam hubungan yang kompleks. Salah satu cara untuk mengurangi kerumitan dalam organisasi adalah dengan berfokus pada bisnis yaitu pada kompetensi utama perusahaan dan melakukan outsourcing untuk hal lain. Komitmen yang kuat akan pencapaian targetanggaran dari manajer akan berpengaruh positif pada peningkatan kinerja manajerial (Wentzel, 2002).

Perbedaan antara penganggaran tradisional dengan beyond budgeting dapat dilihat dari enam aspek tujuan manajemen kinerja yaitu :

1. Pada tujuan perusahaan secara keseluruhan (goals).Tujuan perusahaan adalah untuk menyeimbangkan kebutuhan perusahaan dengan kemampuan perusahaan untuk memaksimalisasi keuntungan jangka pendek serta keuntungan potensial jangka panjang. Proses penganggaran tradisional mementingkan target tetap tahunan (kontrak kinerja) yang pada akhirnya mendorong tindakan yang berfokus pada hasil jangka pendek. Proses beyond budgeting berfokus pada indeks penilaian kinerja relatif dengan tujuan yang aspiratif, yang mendorong keberhasilan persaingan yang berkesinambungan.

2. Perbedaan dalam sistem penghargaan (rewards). Sistem penghargaan bertujuan untuk menyediakan dasar yang efektif dalam memotivasi dan memberikan hadiah pada kinerja. Proses penganggaran tradisional memberikan insentif yang bersifat individual, sehingga mendorong sikap yang melindungi keunggulan diri sendiri dan sikap yang berfokus pada kebutuhan untuk memenuhi target. Proses beyond budgeting memberikan penghargaan untuk semua anggota kelompok, sehingga mendorong sikap satu kesatuan dalam kelompok dalam mencapai tujuan bersama. Adanya tekanan dari rekan-rekan kerja juga mendorong timbulnya keinginan untuk melakukan pengembangan diri secara terus-menerus.

3. Perbedaan dalam perencanaan (plans) yang bertujuan untuk mendorong tindakan memaksimalisasi kesempatan dalam pasar. Proses penganggaran tradisional menyediakan perencanaan tahunan, yang merupakan suatu pendekatan yang mendorong strategi "produksi dan jual" dan mengutamakan perusahaan. Proses beyond budgeting menggunakan strategi berdasarkan kejadian yang terjadi, yang merupakan pendekatan yang bersifat responsif dan lebih mengutamakan pelanggan.

4. Perbedaan pada penggunaan sumber daya (resources). Sumber daya diharapkan dapat tersedia untuk mendukung tindakan-tindakan strategis perusahaan. Proses penganggaran tradisional mengalokasi sumber daya secara terpusat, sehingga menghalangi respon yang cepat dan mendorong timbulnya waste. Proses beyond budgeting mengalokasikan sumber daya sesuai dengan kebutuhan sehingga dapat mendorong respon yang cepat dn mengurangi timbulnya waste.

5. Perbedaan dalam koordinasi (coordination) untuk menyelaraskan tindakan yang dilakukan di seluruh bisnis. Proses penganggaran tradisional menyediakan sistem penganggaran yang bersifat terpusat, sehingga solusi atas masalah yang muncul terkadang membutuhkan waktu yang lama dan pada akhirnya gagal memenuhi kebutuhan pelanggan. Proses beyond budgeting secara dinamis berhubungan langsung dengan permintaan pelanggan, sehingga menyediakan solusi yang cepat dan tepat dalam memenuhi kebutuhan pelanggan. 
6. Pengendalian (controls) dalam menyediakan informasi yang relevan dalam pembuatan keputusan dan pengendalian secara keseluruhan. Proses penganggaran tradisonal menyediakan suatu perbandingan antara kinerja aktual dengan anggaran yang telah dibuat sebelumnya. Perbandingan ini hanya menyatakan baik atau buruknya kinerja, tapi tidak memberikan dasar pembelajaran untuk perbaikan satu kinerja.Proses beyond budgeting memberikan pola informasi yang dibutuhkan bagi pembuatan keputusan dengan pengendalian yang bersifat multi faceted dan multilevel sehingga pengendalian yang dilakukan lebih detail dan menyeluruh. Informasi yang diperoleh juga lebih lengkap dan dapat membantu pembelajaran untuk periode berikutnya, serta mendukung dalam pembuatan keputusan.

Prinsip Beyond Budgeting mengembangkan sebuah model dengan dua belas (12) prinsip: enam berkaitan dengan proses kunci manajemen kinerja (key performance management principles), dan enam berkaitan dengan tindakan kepemimpinan (key leadership principles), yaitu :

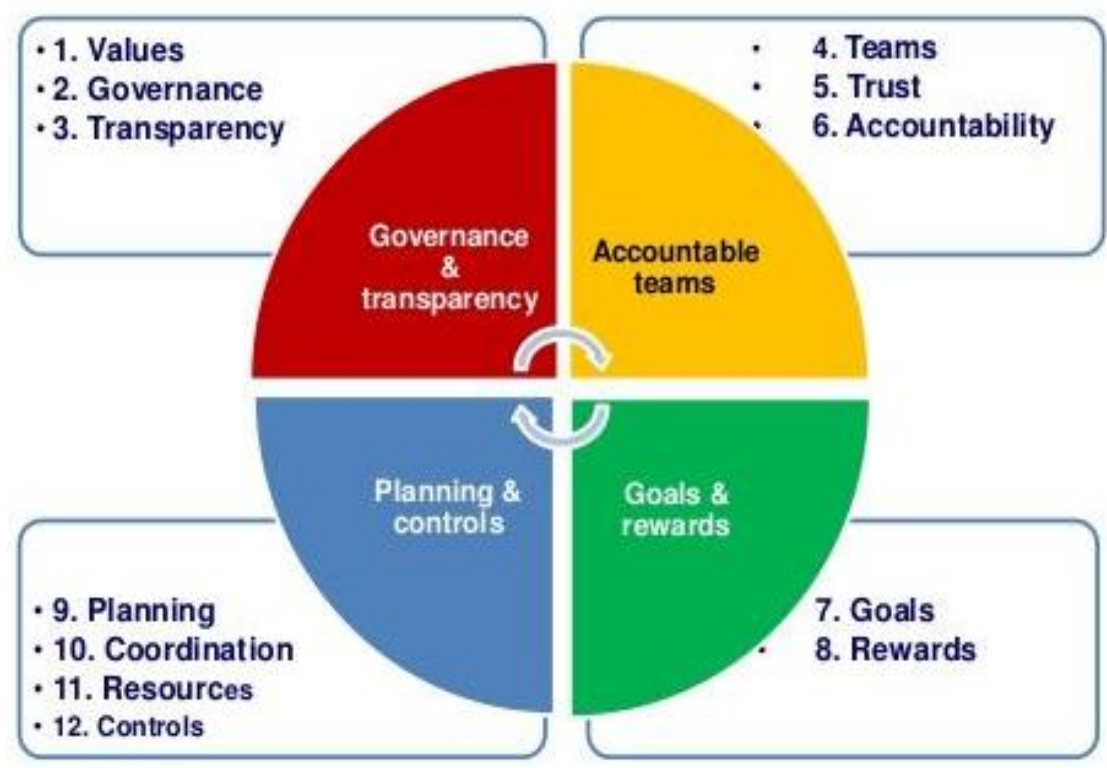

Gambar 1

Sumber: Wentzel, 2002

12 Beyond Budgeting Principles

Terdapat dua elemen penting yang menciptakan lingkungan dengan kebebasan yang tinggi bagi manajer dan karyawan, yaitu budaya manajemen perusahaan dan ketersediaan sistem informasi yang jelas sebagai dasar proses manajemen. Model baru kepemimpinan didasarkan pada prinsip pemberdayaan manajer dan karyawan, serta proses manajemen yang mampu beradaptasi. Prinsip baru kepemimpinan tersebut harus mampu membuka semua potensi manajer dan karyawan dalam menjalankan organisasi agar dapat bereaksi secara tepat dan cepat saat menghadapi kesempatan baru dan risiko pasar. Agar dapat sukses, anggota projek beyond budgeting harus mencakup spesialis pengendalian, manajemen sumber daya manusia, manajemen perubahan, dan ahli komputer. Tidak semua perusahaan mampu menyediakan semua sumber daya yang dibutuhkan tersebut. Perbaikan yang mungkin dilakukan perusahaan untuk mengimplementasikan beyond budgeting, yaitu:

a. Sebuah kerangka tata kelola kerja berdasarkan prioritas dan batas batas yang jelas. Hal ini memungkinkan tim garis depan untuk mengambil keputusan. Seorang pemimpin dan gaya manajemen yang mendukung anggota kelompok dapat mendorong semangat dalam memberikan layanan terbaik bagi pelanggan,

b. Sebuah iklim kinerja tinggi berdasarkan pada kesuksesan yang terlihat dan relatif di semua tingkatan. Hal ini mempromosikan review kinerja berbasis rekan, kompetisi internal dan rasa kedekatan dengan pelanggan,

c. Kelompok lini depan dengan kebebasan untuk mengambil keputusan sesuai dengan prinsip-prinsip tata kelola dan tujuan strategis perusahaan. Hal ini mempromosikan standar yang tinggi, harapan yang lebih tinggi dan benchmark,

d. Tim diberitanggung jawab untuk menciptakan sistem nilai. Hal ini menciptakan dan berdayakan semua unit-unit kecil dalam perusahaan, yang memiliki kebebasan untuk mengelola sumber daya mereka sendiri, namun tetap akuntabel,

e. Tim berfokus pada hasil yang diterima pelanggan. Hal ini mengarah ke akuntabilitas yang lebih besar serta pelanggan yang lebih puas dan diuntungkan,

f. Sistem informasi yang terbuka dan etis. Hal ini menghasilkan informasi yang lebih dapat diandalkan, transparansi yang lebih besar dan pelaporan yang lebih etis . 
Pada sistem penganggaran tradisional, target ditetapkan berdasarkan angka finansial dan dinegosiasikan secara terpusat. Pada beyond budgeting, target didasarkan pada indikator kunci kinerja (key performance indicators) yang tinggi, seperti, rasio return on capital, free cash flows atau cost to income. Penilaian kinerja tidak lagi dilakukan untuk jangka panjang (tahunan), tetapi dilakukan dalam rentang waktu yang lebih singkat secara teratur dan bersifat rolling serta desentralisasi.
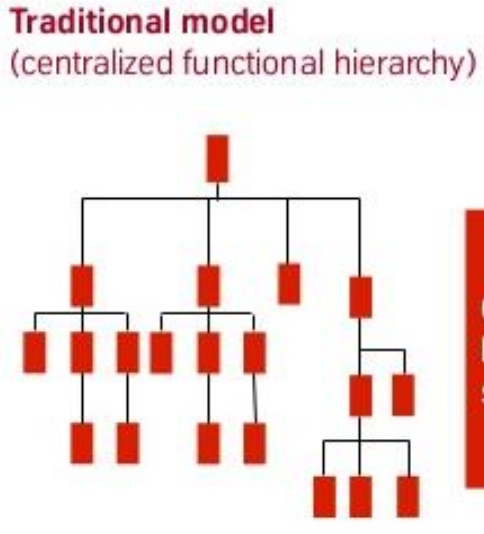

- "Bosses" rule!
- Top-down
command and control
- Top management
is always in charge
- Centralized leadership

\section{New model \\ (decentralized leadership network)}
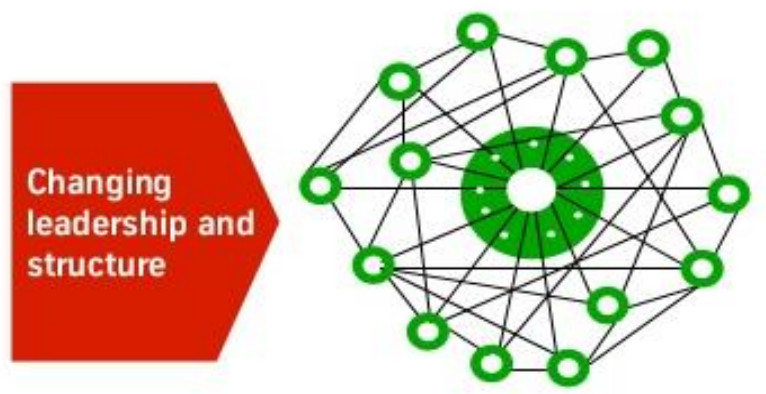

"The market" rules!
- Outside-in
sense and respond
- Front-line teams are always
in charge
- Devolved leadership

Gambar 2

From Hierarchy to Network Structure

Sumber: Seminar - Beyond Budgeting

Sumber masalah yang ada pada sistem perencanaan dan penganggaran terletak pada pandangan persuasif bahwa perusahaan adalah sebuah mesin penghasil uang, bukan sebuah kelompok manusia yang kompleks, memiliki kehidupan yang berbeda-beda, dapat berubah seiring berjalannya waktu, dan bereaksi terhadap perubahan lingkungan.

\section{Beyond Budgeting: empower and coach}

By contrast, Beyond Budgeting is grounded in empowering and coaching. The core approach: results improve when management relinquishes control and allows business units and teams to leverage customer proximity and act autonomously on goals, plans, and initiatives. The executive role shifts toward a coaching role characterized by entrusting business units and teams with executing on high-level goals - and then challenging and supporting them as needed. Managers and employees are seen as trustworthy and entirely capable of assuming responsibility for actions and outcomes. They see their work from a holistic, partner-based vantage point, and their efforts are characterized by high levels of collaboration and cooperation. Executive management supports high levels of access to needed information as this transparency is essential to better and quicker decision making, as well as enhanced accountability ( Arthur F. Rothberg, 2011)

Beyond budgeting berusaha menghubungkan ide tersebut kedalam organisasi dan membentuk suatu human network dengan berbagai cara manajemen kinerja (performance management ). Agar dapat berhasil, implementasi beyond budgeting harus dilakukan dengan memberikan pemahaman yang jelas dalam melakukan perubahan dengan menjelaskan semua keunggulan yang akan diperoleh. Manajer harus dapat memutuskan dengan hati-hati tingkat desentralissi yang memungkinkan untuk dilakukan dalam organisasi mereka, serta perlu ada sebuah kerangka kerja dengan prioritas dan batasan yang jelas. Manajer juga perlu mengembangkan etos kerja yang didasarkan pada persaingan sehat dalam mencapai kesuksesan dengn memberikan kebebasan bagi anggota kelompok lini depan untuk mengambil keputusan. Dengan demikian, kepercayaan dan keterbukaan dalam organisasi merupakan hal yang sangat penting.

Financial control is defined as being assisted by the provision of financial information to management by the accountant and the use of such techniques as budgetary control and standard costing, which highlight and analyses any variances (Daum, 2002). The Beyond Budgeting model has received a lot of attention recently from academics and practitioners alike. Put simply, it prescribes the replacement of fixed performance targets with a system that relies on control through peer reviews, openness and transparency. This should release managers' time and give them more freedom to manage. Research has shown that the model is typically adopted by companies employing 1,000 or more 
people. We wanted to discover the extent to which Beyond Budgeting is being adopted by much smaller enterprises eg, micro-organisations and small businesses engaged in e-commerce - and whether it's appropriate for them. (Mark Pilkington and David Crowther, , 2007). The results indicate that participative budgeting is most important for planning and control, specifically vertical information sharing and co-ordinating interdependence, and that specific reasons for participative budgeting are correlated with three of the antecedents. Finally, directions for future research on participative budgeting are presented. (J.F.Shields, M.D.Shields, 1998)

Berikut analisa perbandingan bagaimana mengevaluasi poin-poin penting kinerja manajemen menggunakan 2 konsep yang berbeda yaitu berdasarkan Konsep Beyond Budgeting dan Konsep menurut perusahaan.

1. Melakukan perhitungan persentase tingkat kesesuaian dari hasil analiasi tabel perbandingan antara konsep beyond budgeting dengan konsep evaluasi kinerja menurut perusahaan .

Perhitungan presentase :

Tidak sesuai $=\frac{\text { Total } \text { nilai sesuai } \text { yang diperoleh }}{\text { Total nilai perbandingan }} \times 100 \%$

Sesuai $=\frac{\text { Total nilai sesuai } \text { yang diperoleh }}{\text { Total nilai perbandingan }} \times 100 \%$

Jika hasil dari perhitungan presentase kesesuaian dinyatakan lebih besar dari lebih besar dari 80\% (tingkat asumsi wajar) . maka dapat disimpulkan bahwa konsep beyond budgeting sudah diterapkan dalam konsep evaluasi kinerja perusahaan.

2. Deskripsikan perbandingan antara konsep beyond budgeting dengan konsep evaluasi kinerja manajemen.

3. Kemudian dari langkah tadi diperoleh deskripsi mengenai kemungkinan penerapan konsep beyond budgeting dalam perusahaan yaitu apakah konsep beyond budgeting sudah diterapkan atau konsep beyond budgeting belum diterapkan pada perusahaan.

\section{Analisa data dengan kuestionair}

Untuk menjawab permasalahan apakah konsep beyond budgeting dapat diterapkan dalam evaluasi kinerja perusahaan (manajemen), maka digunakan analisis kuesioner. Langkah-langkah yang ditempuh adalah sebagai berikut:

1. Menyebarkan kuesioner kepada lima manajer perusahaan. Kuesioner ditujukan untuk memperoleh data kesiapan sumber daya manusia yaitu lima manajer perusahaan dalam menerapkan konsep beyond budgeting.

2 Melakukan analisis kuesioner menggunakan skor nilai angka interval 1-7 (dari 1=sangat buruk sampai 7=sangat baik) digunakan untuk menganalisis dapat atau tidaknya sumber daya manusia dalam menerapkan konsep beyond budgeting.

Tabel 1

Analisis Perbandingan Evaluasi Kinerja Manajemen Berdasarkan Konsep Beyond budgeting dengan Evaluasi Kinerja menurut

Perusahaan

\begin{tabular}{|c|c|c|c|}
\hline $\begin{array}{c}\text { Komponen Yang } \\
\text { Diband ingkan }\end{array}$ & $\begin{array}{c}\text { Evaluasi Kinerja Manajemen Berdasarkan } \\
\text { Konsep Beyond Budgeting } \\
\end{array}$ & $\begin{array}{c}\text { Evaluasi Kinerja Menurut } \\
\text { Perusahaan } \\
\end{array}$ & $\begin{array}{l}\text { Analisis Dan } \\
\text { Kesimpulan }\end{array}$ \\
\hline 1. Target & $\begin{array}{l}\text { Target dibuat secara relatif a tau terg antung pada } \\
\text { kondisi pasar dan dievaluasi secara bergulir. } \\
\text { - Evaluasi target didasarkan pada KPI (key } \\
\text { performance indica tor). Misalnya profit KPI atau } \\
\text { Unit Cost KPI } \\
\end{array}$ & & \\
\hline 2. Penghargaan & $\begin{array}{l}\text { Menilai penghargaan berdasarkan evaluasi } \\
\text { kinerja tim } \\
\text { - Menilai penghargaan dengan review oleh } \\
\text { panel rekan sekerja pada akhir tahun. }\end{array}$ & ........ & ....... \\
\hline 3. Rencana & $\begin{array}{l}\text { Proses pendekatan pelanggan dilakukan sebagai } \\
\text { dasar evaluasi dalam penyusunan rencana } \\
\text { strategi manajemen. } \\
\text { - Untuk mencapai rencana atas sasaran jangka } \\
\text { menengah, manajer dapat melakukan tindakan } \\
\text { apapun tetapi masih dalam kaedah } \\
\text { kepemimpinan dan batas-batas strategi. }\end{array}$ & $\cdots$ & \\
\hline 4. Sumber Daya & $\begin{array}{l}\text { Evaluasi sumber daya dilakukan secara } \\
\text { decentralized (tidak terpusat) untuk merespons } \\
\text { kebutuhan sumber daya perusahaan secara cepat. }\end{array}$ & ........ & $\cdots$ \\
\hline 5. Koordinasi & $\begin{array}{l}\text { Koordinasi secara decentralized sebagai } \\
\text { evaluasi kinerja manajemen dalam memenuhi } \\
\text { kebutuhan pelanggan. } \\
\text { Koordinasi dan evaluasi atas tindakan dalam } \\
\text { memenuhi ke butuhan pelanggan dilakukan } \\
\text { dengan perse tujuan tingkat jasa atau unit bisnis. } \\
\text { - Pengendalian diciptakan secara multifaceted } \\
\text { maupun multi level dalam siklus ang garan. }\end{array}$ & & \\
\hline
\end{tabular}

Sumber: olahan data 
Tabel 2

Skoring Kuesioner Kinerja Manajemen

\begin{tabular}{|c|c|c|c|c|c|c|c|c|}
\hline \multirow{3}{*}{ No } & \multirow{3}{*}{ Pertanyaan } & \multicolumn{7}{|c|}{ S k o r } \\
\hline & & \multicolumn{7}{|c|}{ Sangat buruk - -----> Sangat baik } \\
\hline & & 1 & 2 & 3 & 4 & 5 & 6 & 7 \\
\hline 1 & Target & & & & & & & \\
\hline 2 & Penghargaan & & & & & & & \\
\hline 3 & Rencana & & & & & & & \\
\hline 4 & Koordinasi & & & & & & & \\
\hline 5 & Sumber Daya & & & & & & & \\
\hline 6 & Pengendalian & & & & & & & \\
\hline
\end{tabular}

Sumber: olahan data

\section{METODE}

Penelitian ini menggunakan metode kualitatif karena peneliti ingin mengetahui dan menganalisis secara mendalam tentang bagaimana membuat dan menganalisa suatu budget yang efektif dan tepat guna yang dapat digunakan untuk pemimpin perusahaan dalam menentukan budget yang akan menjadi acuan pada periode mendatang. Data primer berasal dari perusahaan pada saat peneliti melakukan penelitian dimana sebagian besar data adalah datadata keuangan perusahaan. Teknik analisis data yang digunakan dalam penelitian ini adalah model interaktif dengan melalui analisa deskriptif kualitatif dilakukan dengan membandingkan fakta yang diperoleh di perusahaan dengan peraturan, sumber dan teori yang relevan, sehingga dapat diperoleh jawaban dan kesimpulan yang akurat.

\section{HASIL DAN PEMBAHASAN}

Tabel 2

Hasil Perbandingan Konsep Beyond Budgeting Vs Evaluasi Menurut Perusahaan

\begin{tabular}{|c|c|c|c|}
\hline $\begin{array}{r}\text { Komponen Perbandingangan } \\
\text { Evaluasi Kinerja } \\
\end{array}$ & $\begin{array}{c}\text { Evaluasi Kinerja Manajemen } \\
\text { Berdasarkan Konsep Beyond Budgeting }\end{array}$ & $\begin{array}{c}\text { Evaluasi Kinerja menjurut } \\
\text { Manajemen }\end{array}$ & $\begin{array}{c}\text { Analisis Ke simpulan } \\
\text { Evaluasi Kinerja }\end{array}$ \\
\hline Target & $\begin{array}{l}\text { Target dibuat secara relatif atau } \\
\text { tergantung pada kondisi pasar dan } \\
\text { dievaluasi secara bergulir. } \\
\text { Evaluasi target didasarkan pada KPI } \\
\text { (hey performance indic ator) misalnya } \\
\text { profit KPI atau unit cost KPI. }\end{array}$ & $\begin{array}{l}\text { Target dibuat dan disesuaikan } \\
\text { dengan perubahan yang terjadi } \\
\text { dilingkungan internal maupun } \\
\text { eksternal perusahaan serta } \\
\text { dievaluasi secara bergulir } \\
\text { (rolling). } \\
\text { Target dievaluasi berdasarkan } \\
\text { hal-hal yang telah disepakati } \\
\text { sebelumnya. }\end{array}$ & Sesuai \\
\hline Penghargaan & $\begin{array}{l}\text { Menilai pengharg aan berdasarkan } \\
\text { evaluasi kinerja tim. } \\
\text { Menilai penghargaan dengan review } \\
\text { oleh panel rekan sekerja pada akhir } \\
\text { tahun. }\end{array}$ & $\begin{array}{l}\text { Pemberian penghargaan } \\
\text { berdasarkan hasil evaluasi } \\
\text { kerja satu tim. } \\
\text { Penghargaan terhadap } \\
\text { karyawan dinilai dan } \\
\text { dievaluasi oleh pihak } \\
\text { manajemen dan direksi pada } \\
\text { akhir tahun. }\end{array}$ & $\begin{array}{l}\text { Sesuai } \\
\text { Tidak Sesuai }\end{array}$ \\
\hline
\end{tabular}

Sumber: olahan data

Tabel 3

Hasil Perbandingan Konsep Beyond Budgeting Vs Evaluasi Menurut Perusahaan

\begin{tabular}{|c|c|c|c|}
\hline \begin{tabular}{|l|} 
Komponen \\
Perbandingan \\
Evaluasi Kinerja
\end{tabular} & $\begin{array}{c}\text { Evaluasi Kinerja Manajemen } \\
\text { Berd asarkan Konsep Beyond } \\
\text { Budgeting }\end{array}$ & $\begin{array}{c}\text { Evaluasi Kinerja menurut } \\
\text { Manajemen }\end{array}$ & $\begin{array}{c}\text { Analisis/Kesimpulan } \\
\text { Evaluasi Kinerja }\end{array}$ \\
\hline Rencana & $\begin{array}{l}\text { Proses pendekatan pelanggan dilakukan } \\
\text { sebagai dasar evaluasi dalam } \\
\text { penyusunan rencana strategi } \\
\text { manajemen. } \\
\text { Untuk mencapai rencana atas sasaran } \\
\text { jangka pendek, manajer dapat } \\
\text { melakukan tindakan apapun tetapi } \\
\text { masih dalam kaedah kepemimpinan } \\
\text { dan batas-batas stra tegi. }\end{array}$ & $\begin{array}{l}\text { Keinginan pelanggan dijadikan } \\
\text { dasar untuk menyusun rencana } \\
\text { dan proses evaluasi rencana } \\
\text { stra tegi perusa haan oleh } \\
\text { manajemen. } \\
\text { Manajer belum dapat } \\
\text { menerapkan kebijakan- } \\
\text { kebijakan atas sasaran yang } \\
\text { telah dibuat dan dijalankan } \\
\text { dikarenakan masih terpengaruh } \\
\text { oleh pemilik perusahaan. }\end{array}$ & Tidak sesuai \\
\hline Sumber daya & $\begin{array}{l}\text { Evaluasi sumber daya dilakukan } \\
\text { secara Decentralized (tidak terpusat) } \\
\text { untuk merepond kebutuhan sumber } \\
\text { daya perusahaan secara cepat. }\end{array}$ & $\begin{array}{l}\text { Evaluasi sumber daya } \\
\text { dilakukan secara centralized } \\
\text { yaitu terpusat pada } \\
\text { direktur/pemilik perusahaan. }\end{array}$ & Tidak sesuai \\
\hline Koordinasi & $\begin{array}{l}\text { Koordinasi secara desentralisasi sebagai } \\
\text { evaluasi kinerja manajemen dalam } \\
\text { memenuhi kebutuhan pelangan. }\end{array}$ & $\begin{array}{l}\text { Koordinasi yang dirancang pada } \\
\text { perusahaan dihubungkan dengan } \\
\text { perkembangan permintaan dan } \\
\text { keinginan pelanggan. }\end{array}$ & Se suai \\
\hline Pengendalian & $\begin{array}{l}\text { Memanfaatkan manajemen tools yang } \\
\text { ada sebagai alat evaluasi dan } \\
\text { pengendalian kinerja manajemen. } \\
\text { Contohnya EVA, bench marking, } \\
\text { balanced score scrad dan activith based } \\
\text { management. }\end{array}$ & $\begin{array}{l}\text { Pengendalian dilakukan dengan } \\
\text { membandingkan rencana } \\
\text { anggaran dengan realisasi } \\
\text { anggaran. }\end{array}$ & Se suai \\
\hline
\end{tabular}

Sumber: olahan data 
Tabel 4

Kesiapan Sumber Daya Perusahaan dalam Menerapkan Konsep Beyond Budgeting.

\begin{tabular}{|c|c|c|c|c|c|c|c|c|}
\hline \multirow{2}{*}{ Pertanyaan } & \multicolumn{7}{|c|}{ Skor } & \multirow{2}{*}{$\begin{array}{c}\text { Rata rata } \\
\text { skor }\end{array}$} \\
\hline & 1 & 2 & 3 & 4 & 5 & 6 & 7 & \\
\hline \multirow{5}{*}{$\begin{array}{l}\text { Target } \\
\text { Usaha Anda dalam mening katkan laba perusa haan. Usaha } \\
\text { anda dalam meningka tkan jumlah penjualan produk. } \\
\text { Usaha anda dalam meningkatkan jumlah pelanggan } \\
\text { (customer). } \\
\text { Usaha anda dalam memperluas pangsa pasar. }\end{array}$} & & & & & & & & \\
\hline & o & 0 & 0 & 0 & 2 & 2 & 1 & $5,8 *$ \\
\hline & 0 & 0 & 0 & 1 & 1 & 2 & 1 & 5,6 \\
\hline & 0 & 0 & 0 & 0 & 1 & 2 & 2 & 6,2 \\
\hline & o & 0 & 0 & 0 & 2 & 2 & 1 & 5,8 \\
\hline \multirow{3}{*}{$\begin{array}{l}\text { Penghargaan } \\
\text { Anda mampu mempromosikan karyawan di divisi anda } \\
\text { yang berprestasi untuk naik jabatan. } \\
\text { Anda mampu menilai penghargaan yang akan diberikan } \\
\text { kepada karyawan dengan review panel rekan sekerja } \\
\text { berdasarkan kinerja akhir tahun. }\end{array}$} & & & & & & & & \\
\hline & 0 & 0 & 0 & 1 & 1 & 3 & 0 & 5,6 \\
\hline & 0 & 0 & 0 & 0 & 5 & 0 & 0 & 5 \\
\hline \multirow{4}{*}{$\begin{array}{l}\text { Perencanaan } \\
\text { Anda mampu memberikan kontribusi dalam } \\
\text { menentukan tujuan umum perusahaan. } \\
\text { Anda mampu memberikan kontribusi dalam menentukan } \\
\text { kebijakan perusahaan. } \\
\text { Anda mampu menentukan langkah-langkah yang akan } \\
\text { diambil (penjadwalan kerja, anggaran dan program } \\
\text { kerja). }\end{array}$} & & & & & & & & \\
\hline & 0 & 0 & 0 & 0 & 1 & 4 & 0 & 5,8 \\
\hline & 0 & 0 & 0 & 0 & 2 & 2 & 1 & 5,8 \\
\hline & o & 0 & 0 & 0 & 2 & 2 & 1 & 5,8 \\
\hline \multirow{3}{*}{$\begin{array}{l}\text { Sumberdaya } \\
\text { Anda mampu menyeleksi orang-orang yang akan bekerja } \\
\text { di divisi Anda. } \\
\text { Anda mampu menempatkan orang-orang yang sesuai } \\
\text { dengan kemampuannya pada divisi Anda. }\end{array}$} & & & & & & & & \\
\hline & 0 & 0 & 0 & 2 & 0 & 2 & 1 & 5,4 \\
\hline & o & 0 & 0 & 0 & 2 & 2 & 1 & 5,8 \\
\hline \multirow{3}{*}{$\begin{array}{l}\text { Koord inasi } \\
\text { Anda mampu memberikan informasi yang dibutuhkan } \\
\text { divisi lain. } \\
\text { Anda mampu menyesuaikan program kerja dengan } \\
\text { kebijakan dalam menyampaikan informasi yang } \\
\text { dibutuhkan antar divisi. }\end{array}$} & & & & & & & & \\
\hline & & 0 & 0 & 1 & 2 & 1 & 1 & 5,4 \\
\hline & o & 0 & 0 & 0 & 1 & 4 & 0 & 5,8 \\
\hline \multirow{4}{*}{$\begin{array}{l}\text { Representa tif } \\
\text { Anda mampu memberikan informasi mengenai hal yang } \\
\text { sedang tren saat ini yang nantinya akan bermanfaat bagi } \\
\text { divisi anda. } \\
\text { Anda mampu menyampaikan informasi meng enai divisi } \\
\text { Anda melalui rapat. }\end{array}$} & & & & & & & & \\
\hline & & 0 & 0 & 0 & 1 & 3 & 1 & 6 \\
\hline & & 0 & 0 & 0 & 2 & 2 & 1 & 5,8 \\
\hline & & & & & & & & \\
\hline
\end{tabular}

Sumber: olahan data

Catatan: Data yang diambil hanya 1 kuestioneir, sedangkan data 4 kuestioneir lain, tidak ditampilkan.

Perhitungan presentase:

Total nilai sesuai yang diperoleh

Tidak sesuai $=\frac{5}{11} \times 100 \%=45,5 \%$

Sesuai $=\frac{6}{11} \times 100 \%=54,5 \%$

Berdasarkan hasil analisis tabel perbandingan di atas dapat diketahui bahwa evaluasi kinerja manajemen kinerja perusahaan tidak sesuai dengan konsep beyond budgeting. Karena tingkat kesesuaian tidak mencapai $80 \%$ hanya mencapai $54.5 \%$ saja. Oleh karenanya beberapa saran sebagai berikut dapat menjadi pertimbangan :

1. Agar tingkat kinerja perusahaan mencapai target, maka setiap manajer perusahaan lebih fokus dan self improve atas point-point yang sudah ditentukan dan memonitornya secara berkala.

2. Komunikasi dan koordinasi yang baik antar divisi yang terlibat dalam pembuatan budget amat sangat diharuskan. Mengapa?. Karena dalam pembuatan budget, pada umumnya kepentingan masing-masing divisi akan diprioritaskan oleh masing-masing pejabat yang berwenang.

3. Dalam pembuatan budget based Beyond Budget, sebaiknya berlaku prinsip bottom up bukan top down dan oleh karenanya bersifat desentralisasi. Karena fakta dan data dimiliki oleh masing-masing divisi , peran pimpinan adalah memberikan arahan dan pengambil keputusan yang terbaik berdasarkan data dan fakta yang ada.

4. Sistim rolling (bergulir) untuk mengetahui diferensiasi antara budget dan realisasi.

5. Perusahaan melakukan perbaikan terhadap penilaian penghargaan terhadap karyawan yang dilakukan oleh manajemen dan direksi pada akhir tahun dengan menilai penghargaan dengan review oleh panel rekan sekerja pada akhir tahun.

6. Perusahaan melakukan perbaikan dalam proses perencanaan yaitu menghilangkan sistem centralized dalam pembuatan keputusan manajer sehingga manajer tim unit bisnis dapat bergerak leluasa dan bertanggungjawab penuh terhadap kebijakan yang diambil untuk pencapaian target perusahaan.

7. Perusahaan melakukan perbaikan dalam penilaian sumber daya secara centralized dan melakukan perubahan secara adaptive yaitu tidak terpusat pada pemilik perusahaan saja, sehingga dapat mengurangi kesia-siaan sumber daya 
yang terpendam pada satu bagian karena sulit dalam pengendaliaannya, dapat mempercepat pengambilan keputusan, dan mengurangi waste.

\section{SIMPULAN}

1. Di hampir semua bentuk bisnis, lingkungan organisasi bergerak secara radikal, tidak dapat diprediksi, dan juga mengalami pergolakan. Selain itu, ekspektasi kinerja dari pelanggan, pemegang saham, dan pihak-pihak yang memiliki kepentingan dalam perusahaan terus meningkat.

2. Perusahaan modern saat ini menolak sistem yang tersentralisasi serta perencanaan, komando dan pengendalian yang kaku. Beyond budgeting memberikan suatu model manajemen alternatif yang bersifat adaptif dan terdesentralisasi serta bottom up. Model ini mempromosi-kan budaya kepemimpinan yang mendorong persaingan sehat dalam organisasi, yang pada akhirnya akan menciptakan peningkatan kinerja anggota organisasi dan kepuasan bagi pelanggan.

3. Agar dapat berhasil, implementasi beyond budgeting harus dilakukan dengan memberikan pemahaman yang jelas dalam melakukan perubahan dengan menjelaskan semua keunggulan yang akan diperoleh.

4. Manajer harus dapat memutuskan dengan hati-hati tingkat desentralisasi yang memungkinkan untuk dilakukan dalam organisasi mereka, serta perlu ada sebuah kerangka kerja dengan prioritas dan batasan

5. yang jelas. Manajer juga perlu mengembangkan etos kerja yang didasarkan pada persaingan sehat dalam mencapai kesuksesan dengan memberikan kebebasan bagi anggota kelompok lini depan untuk mengambil keputusan. Dengan demikian, kepercayaan dan keterbukaan dalam organisasi merupakan hal yang sangat penting.

6. Namun penerapan Beyond Budgeting tidaklah semudah membalik telapak tangan, terutama bagi perusahaanperusahaan yang telah cukup lama menerapkan traditional budgeting, yakni manajer-manajer perusahaan tersebut kesulitan atau tidak mampu dalam menghadapi masa-masa transisi tersebut. Karena penerapan Beyond Budgeting berarti mereka harus memiliki harapan-harapan yang jelas untuk mereka capai dan mereka harus tertantang untuk mensukseskan penerapan beyond budgeting ini. Tetapi jika perusahaan masih menginginkan sistem penganggaran formal maka Beyond Budgeting dapat menjadi solusi untuk mengatasi beberapa batasan metode tradisional, meskipun masih terdapat kelemahan seperti pengambilan waktu manajemen yang kadang berlebihan sehingga menyebabkan ketidakpuasan dalam prosesnya.

\section{DAFTAR PUSTAKA}

Adisaputro, Gunawan dan Marwan Asri. 2003. Anggaran Perusahaan 1, edisi Ketiga. Yogyakarta: BPFE Yogyakarta Arthur F. Rothberg, 2011, Traditional Budgeting vs. Beyond Budgeting. CFO Edge. Posted in Financial Planning

Daum, J.H. 2002, Beyond Budgeting: A Model for Performance Management and Controlling in the 21st Century. Controlling \& Finance, 5, 33-34.

Mark Pilkington and David Crowther, 2007, Budgeting and Control. Report on their CIMA. Financial Management.

Shields, J.and M. Shields, 1998, Antecedents of Participative Budgeting. Accounting, Organizations and Society, 4976

Wentzel, K., 2002. The Influence of Fairness Perceptions and GoalCommitment on Manager's Performance in a Budget Setting. Behavioral Research in Accounting, 14, 247-271 